\title{
Simulation and Experimental Results for a Photovoltaic System Formed by Monocrystalline Solar Modules
}

\author{
S. Saraiva ${ }^{1}$, R. Melício ${ }^{1,2}$, J.C.O. Matias ${ }^{1}$, C.M.P. Cabrita ${ }^{1}$, and J.P.S. Catalão ${ }^{1,2}$ \\ ${ }^{1}$ University of Beira Interior and CAST, Covilhã, Portugal \\ catalao@ubi.pt \\ ${ }^{2}$ Instituto Superior Técnico and CIEEE, Lisbon, Portugal
}

\begin{abstract}
This paper focuses on the comprehensive modeling, simulation and experimental validation for a photovoltaic system formed by monocrystalline solar modules. The performance of the equivalent circuit model for a solar cell is validated by data measured parameters of photovoltaic modules. Also, this paper brings a novel iterative procedure to find the value of diode ideality factor, series and equivalent shunt resistances.
\end{abstract}

Keywords: Photovoltaic cells, modeling and simulation, experimental validation, iterative procedure.

\section{Introduction}

Renewable energy resources will play a significant role in the world energy supply in the upcoming future. Solar energy is the primary source for other types of renewable energy, except tidal power and geothermal energy, and even the non-renewable and non-nuclear energies are coming from this primary source. It is accessed in almost all parts of the earth and has an excellent sustainability.

A photovoltaic (PV) system directly converts solar energy into electric energy. The main device of a PV system is a solar cell. Cells may be grouped to form arrays and panels. A PV array may be either a panel or a set of panels connected in series or parallel to form large PV systems [1]. Power-electronic converters are usually required to process the electricity from the PV device. Power-electronic converters may be used to regulate the voltage and current at the load, to control the power flow in grid-connected systems, and for implementing the maximum power point tracking (MPPT) on PV systems.

The solar cell is basically a semiconductor diode exposed to light. Solar cells are made of several types of semiconductors using different manufacturing processes [2]. The electrical energy produced by a solar cell depends on its properties and on the incoming solar radiation [3], known as irradiation.

The simplest equivalent electrical circuits approach is a current source in parallel with a diode [4].

Some author's state that the solution with only a single diode model, i.e., current source in parallel to a diode, for modeling a PV system integrated into the electric grid is enough to obtain good results [5]. 
An improved version is the inclusion of a series resistance in the previous equivalent electrical circuit approach, and an extension of this version includes an additional shunt resistance, augmenting the number of parameters from four to five. This version is justified for modeling with improved accuracy and is followed in this paper. The Standard Test Conditions (STC) for solar cells supplies performance parameters under the standard solar spectral distribution at $1000 \mathrm{~W} / \mathrm{m}^{2}$ and cell temperature of $25^{\circ} \mathrm{C}$.

\section{Contribution to Value Creation}

This paper uses an accurate mathematical model of a solar cell with five parameters as a tool to simulate the I-V characteristics of PV modules. The mathematical model for the solar cell with single-diode, series and equivalent shunt resistances is duly implemented in Matlab/Simulink. To test the validity of the model and validate the simulation results, comparisons between simulated and experimental results at STC are presented in this paper. The data measured from the PV modules correspond to a photovoltaic facility [6] at the Instituto Nacional de Engenharia, Tecnologia e Inovação (INETI). Moreover, this paper brings a novel iterative procedure to find the value of diode ideality factor, series and equivalent shunt resistances.

\section{PV Model}

The equivalent circuit model for a solar cell simulation with single-diode, series and equivalent shunt resistances, is shown in Fig. 1.

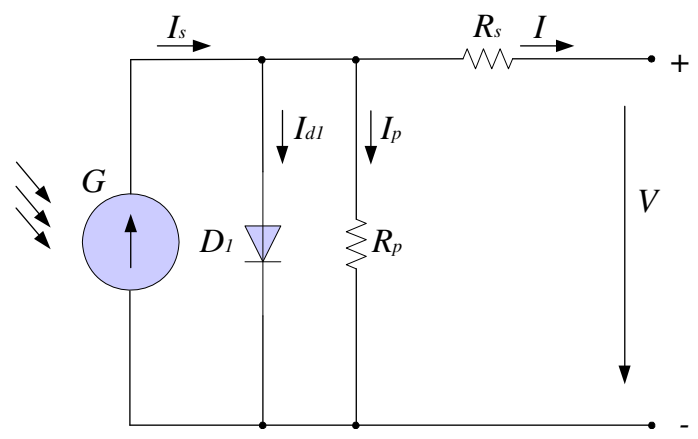

Fig. 1. Equivalent circuit of the solar cell with single-diode, series and equivalent shunt resistances

The equivalent circuit model can be used to simulate an individual cell, a module, an array or a panel. In Fig. $1, G$ is the solar irradiance, $I_{S}$ is the photo generated electric current, $I_{d l}$ is the current at diode $D_{l}, I_{p}$ is the leakage current, $R_{p}$ is the equivalent shunt resistance, $R_{s}$ is the series resistance, $I$ is the output current and $V$ is the output voltage. The thermal voltage of the solar cell is given by: 


$$
V_{T_{1}}=\frac{k T_{1}}{q}
$$

where $q$ is the electron charge, $k$ is Boltzman's constant, and $T_{l}$ is the cell temperature in Kelvin.

The diode saturation current at the operating-cell temperature is given by:

$$
I_{01}=I_{01}^{*}\left(\frac{\mathrm{T}_{1}}{\mathrm{~T}^{*}}\right)^{3} e^{\frac{\varepsilon_{1} q}{m_{1} k}\left(\frac{1}{T^{*}}-\frac{1}{T_{1}}\right)},
$$

where $I_{01}$ is the diode reverse bias saturation current, $I_{01}^{*}$ is the diode reverse bias saturation current at STC, $T^{*}$ is the $p$ - $n$ junction cell temperature at STC in Kelvin, $m_{l}$ is the diode ideality factor, and $\varepsilon_{1}$ is the energy bandgap of the semiconductor.

The I-V characteristic associated with the model shown in Fig. 1 for the solar cell is given by:

$$
I=I_{s}-I_{01}\left[e^{\frac{\left(V+R_{s} I\right)}{m_{1} V_{T_{1}}}}-1\right]-\frac{V+R_{s} I}{R_{p}} .
$$

Equation (3) is an implicit equation: for the same irradiance and $p$ - $n$ junction temperature conditions, implies the use of an iterative equation to determine the output current in function of the output voltage, respectively where [7]:

$$
\begin{aligned}
& R_{s o}=-\left.\frac{d V}{d I}\right|_{V=V_{o c}}, \\
& R_{s h o}=-\left.\frac{d V}{d I}\right|_{I=I_{s c}} .
\end{aligned}
$$

For constant irradiance and $p$ - $n$ junction temperature conditions, the short circuit current $I_{s c}$ it is the greatest value of the current at the cell terminals. The short circuit current $I_{s c}$ is given by:

$$
I_{s c}=I=I_{s}-I_{01}\left(e^{\frac{R_{s} I_{s c}}{m_{1} V_{T_{1}}}}-1\right)-\frac{R_{s} I_{s c}}{R_{p}} .
$$

For constant irradiance and $p$ - $n$ junction temperature conditions, the open circuit voltage $V_{o c}$ is the greatest value of the voltage at the cell terminals. The open circuit voltage $V_{o c}$, using Equation (3), is given by:

$$
V_{o c}=m_{1} V_{T_{1}} \ln \left(\frac{I_{s}}{I_{01}}+\frac{V_{o c}}{R_{p} I_{01}}+1\right) .
$$


The diode ideality factor [8] is given by:

$$
m_{1}=\frac{V_{m}^{*}+R_{s o} I_{m}^{*}-V_{o c}^{*}}{V_{T_{1}}\left[\ln \left(I_{s c}^{*}-\frac{V_{m}^{*}}{R_{s h o}}-I_{m}^{*}\right)-\ln \left(I_{s c}^{*}-\frac{V_{o c}^{*}}{R_{p}}\right)+\frac{I_{m}^{*}}{I_{s c}^{*}-\left(\frac{V_{o c}^{*}}{R_{s h o}}\right)}\right]} .
$$

The output power is given by:

$$
P=V\left[I_{s c}-I_{01}\left(e^{\frac{\left(V+R_{s} I\right)}{m_{1} V_{T_{1}}}}-1\right)-\frac{V+R_{s} I}{R_{p}}\right] .
$$

\section{Iterative Procedure}

PV's maximum power point (MPP) varies with solar irradiance and temperature. Each V-I characteristic curve specify a unique operating point at which maximum possible power is delivered, the MPP, where the PV operates at its highest efficiency [7].

The data considered are: STC cell voltage for maximum power, current for maximum power, open circuit voltage, and short circuit current.

The goal for the novel iterative procedure proposed in this paper is to find the value of diode ideality factor, series and equivalent shunt resistances, with a very good approximation in the neighborhood around the maximum of the I-V curve, since this is the aimed operation point.

Hence, coinciding with the maximum power at STC is not fully imposed, nor at the cell voltage for maximum power at STC or the cell current for maximum power at STC, but the error is aimed at being very small.

In the proposed iterative procedure, the series resistance must be slowly incremented starting from a null value. Adjusting the I-V curve to match the cell reference condition requires finding the curve for several values of series and equivalent shunt resistances.

The Newton-Raphson method was used in the proposed iterative procedure due to the ability to overcome undesired behaviors [9].

The flowchart of the proposed iterative procedure to adjust the I-V output characteristics of the solar cell is shown in Fig. 2.

Plotting the I-V characteristic curves requires solving (3) for $I \in\left[0, I_{s c}\right]$ and $V \in\left[0, V_{o c}\right]$. However, $I=f(V, I)$ or $V=f(I, V)$ are implicit equations.

Hence, numerical methods have to be used, imposing an adequate formalism. For instance, writing the I-V as $g(V, I)=I-f(V, I)=0$ points are rather easily obtained by numerically solving for a set of terminal voltage values, thus obtaining the corresponding set of output current points. 


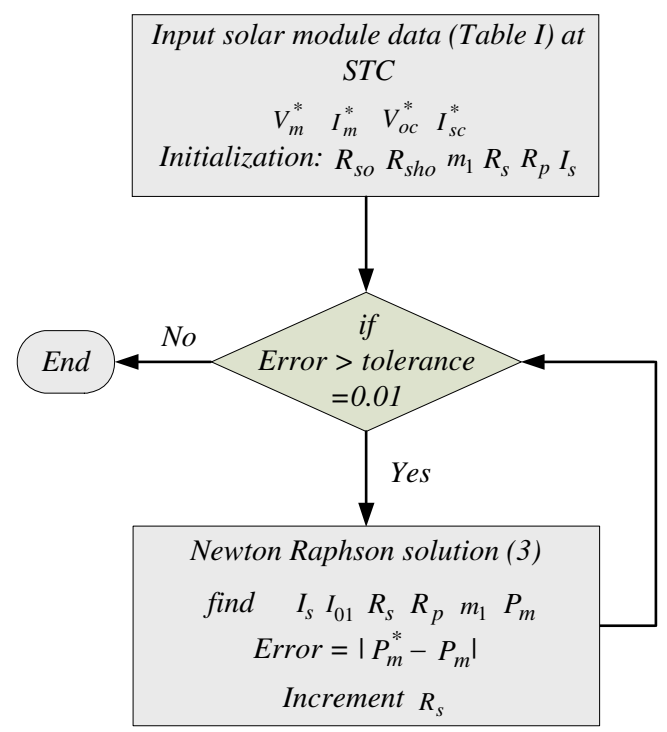

Fig. 2. Flowchart of the proposed iterative procedure to adjust the I-V output characteristics of the solar cell

\section{Simulation and Experimental Results}

For each tested PV module, its characteristic curve is measured outdoors, quasisimultaneously with the measurement of the reference unit I-V curve. The I-V curve is then translated to STC conditions by using the procedure described in IEC 60891 [10]. Both I-V curves are extrapolated to STC, according with the usual procedure [11]. The I-V curve tracer is shown in Fig. 3.

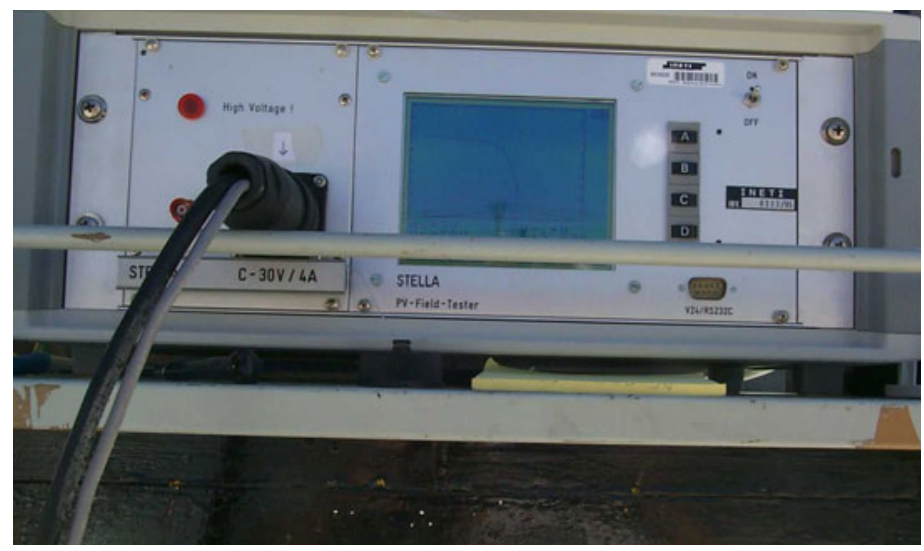

Fig. 3. The I-V curve tracer 
The PV system formed by two monocrystalline solar panels series-connected is shown in Fig. 4.

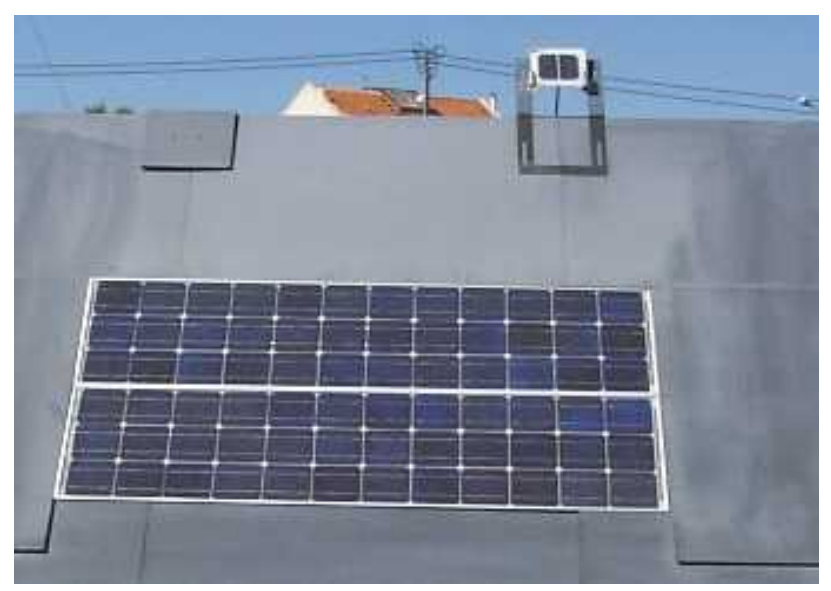

Fig. 4. PV system formed by two monocrystalline solar modules series-connected

The monocrystalline technology modules tested were Isofotón I53. Table 1 summarizes the data for the silicon monocrystalline solar module Isofotón I53 at STC [12].

Table 1. Solar module data for Isofotón I53 module

\begin{tabular}{cc}
\hline Parameter & Solar cell \\
\hline Voltage at maximum power $V_{m}^{*}$ & $17.4 \mathrm{~V}$ \\
\hline Current at maximum power $I_{m}^{*}$ & $3.05 \mathrm{~A}$ \\
\hline Open circuit voltage $V_{o c}^{*}$ & $21.65 \mathrm{~V}$ \\
\hline Short circuit current $I_{s c}^{*}$ & $3.27 \mathrm{~A}$ \\
\hline Number of cells for module & 36 \\
\hline Temperature coefficient of $\beta_{o c}$ & $-80 \mathrm{mV} /{ }^{\circ} \mathrm{C}$ \\
\hline Temperature coefficient of $\alpha_{s c}$ & $1.748 \mathrm{~mA} /{ }^{\circ} \mathrm{C}$ \\
\hline NOCT & $47^{\circ} \mathrm{C}$ \\
\hline
\end{tabular}

In order to test the validity of the proposed model for the Isofotón I53, comparisons between the simulated and experimental results at STC were carried out. The I-V comparison is shown in Fig. 5. 


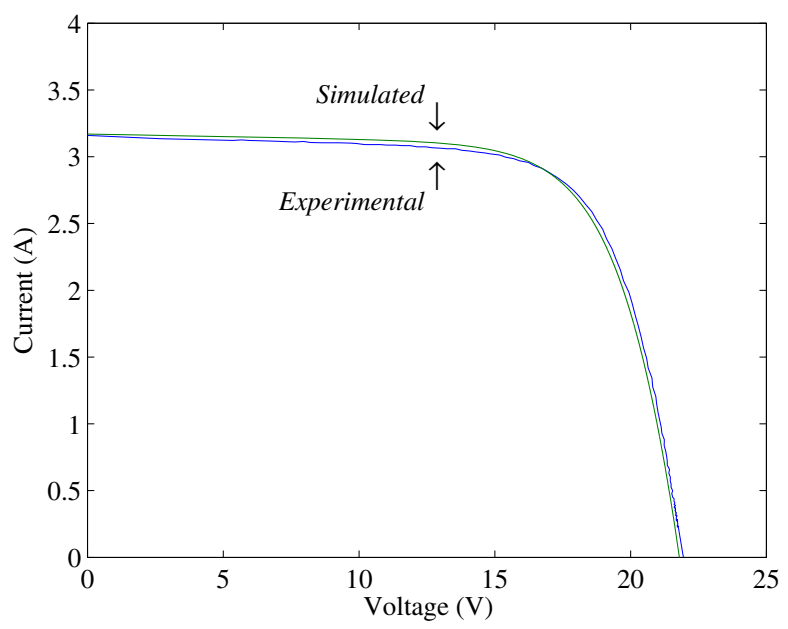

Fig. 5. I-V comparison between the simulated model and the experimental results at STC The P-V comparison is shown in Fig. 6.

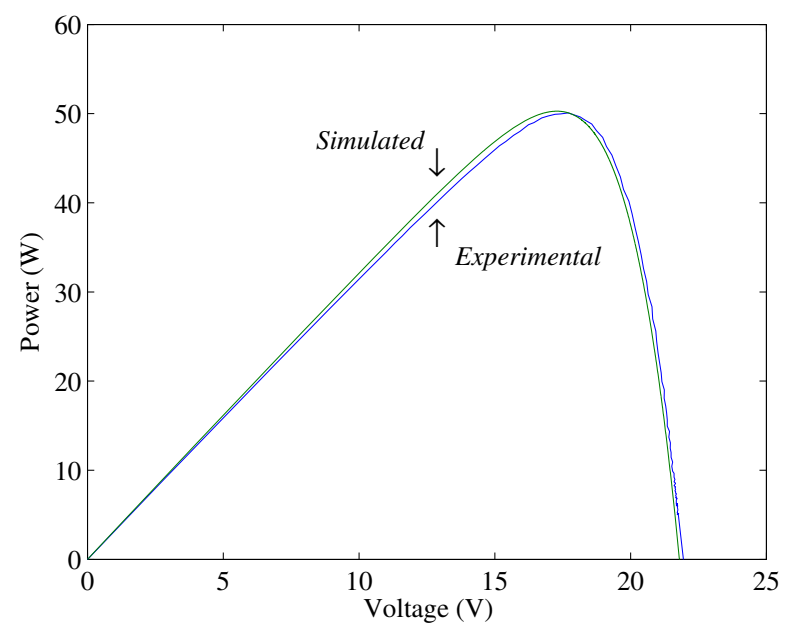

Fig. 6. P-V comparison between the simulated and the experimental results at STC

A very good agreement is verified between the simulated and the experimental results at STC, validating the mathematical model implemented in Matlab/Simulink and the novel iterative procedure proposed employing the Newton-Raphson method.

\section{Conclusions}

A solar cell model with single-diode, series and equivalent shunt resistances, is considered in this paper. The assessment of parameters by a novel iterative procedure 
employing the Newton Raphson method is proposed. The novel iterative procedure computes the main information regarding the use of this model. A very good agreement is verified between the simulated and the experimental results at standard test conditions.

Acknowledgment. The authors gratefully acknowledge to Ms. L. Giacobbe for providing the measured data from the PV modules at INETI.

\section{References}

1. Villalva, M.G., Gazoli, J.R., Filho, E.R.: Comprehensive approach to modeling and simulation of photovoltaic arrays. IEEE Trans. Power Electronics 24, 1198-1208 (2009)

2. Sedra, A.S., Smith, K.C.: Microelectronic Circuits. Oxford Univ. Press, London (2006)

3. Eltawil, M.A., Zhao, Z.: Grid-connected photovoltaic power systems: Technical and potential problems-A review. Renewable and Sustainable Energy Reviews 14(1), 112129 (2010)

4. Ishaque, K., Salam, Z., Taheri, H.: Simple, fast and accurate two-diode model for photovoltaic modules. Solar Energy Materials and Solar Cells 95, 586-594 (2011)

5. Luque, A., Hegedus, S.: Handbook of Photovoltaic Science and Engineering. John Wiley and Sons, West Sussex (2003)

6. Giacobbe, L.: Validação de modelos matemáticos de componentes de sistemas fotovoltaicos: Master Thesis (in Portuguese). IST/DEEC, Lisboa (2005)

7. Jiang, J.-A., Huang, T.-L., Hsiao, Y.-T., Chen, C.-H.: Maximum power tracking for photovoltaic power systems. Tamkang Journal of Science and Engineering 8, 147-153 (2005)

8. Dzimano, B.S.G.: Modeling of photovoltaic systems: Master Thesis. State University, Ohio (2008)

9. Walker, G.R.: Evaluating MPPT topologies using a Matlab PV model. Journal of Electrical \& Electronics Engineering 21, 49-56 (2001)

10. Procedures for temperature and irradiance corrections to measured $\mathrm{I}-\mathrm{V}$ characteristics of crystalline silicon photovoltaic devices, IEC 60891

11. Photovoltaic devices-Part 1: Measurement of photovoltaic (PV) current-voltage characteristics, IEC 60904-1

12. Isofotón Photovoltaic Products Information, http: / / www . isofoton. com 